\title{
Correspondence
}

Contents: Informed consent in chronic schizophrenia/Lithium revisited/GP monitoring of lithium levels/Long-term treatment with clozapine in schizophrenia/Psychological debriefing techniques/Brief psychotic episodes in puberty/ Non-Alzheimer dementias in young patients/ Quality of statistics in psychiatric research

\section{Informed consent in chronic schizophrenia}

SIR: In his description of the complexity involved in judgements of probabilities Jones (1995) implies that a high threshold of competence is uniformly required to provide consent. The fundamental question is not whether the patient has cognitive deficits but whether he or she is able to pass the test for competence as required by law.

Jones quotes the definition of consent contained in the Department of Health's 1993 Code of Practice for the Mental Health Act 1983, which focuses on understanding treatment information. The Code of Practice talks of the patient understanding the nature of the treatment 'in broad terms'. Section 15.11 cautions the reader that: "Capacity to consent is variable in people with mental disorder and should be assessed in relation to the particular patient, at the particular time, as regards the particular treatment proposed". Recent case law has amplified the meaning of capacity to make treatment decisions with a 'three stage' test: a person must be capable of: i) comprehending and retaining relevant treatment information; ii) believing it; and iii) weighing it in the balance to arrive at a choice $(\operatorname{Re} C, 1994)$.

In a study that required patients to meet all three criteria for competence similar to those accepted in English Law ('understanding', 'appreciation', and 'reasoning'), only $52 \%$ of patients hospitalised with schizophrenia were considered to have impaired decision making ability concerning treatment for the disorder (Grisso \& Appelbaum, 1995).

Jones states that neuropsychological tests may help clinicians make assessments of whether patients are fit to give informed consent, but in practice the law and clinicians require a demon- stration of an individual's competence to consent to a specific issue, not a test of general ability. The required threshold for competence varies in relation to the seriousness of the decision being made, and an excessively high level may unnecessarily deny patients their autonomy. For example, in deciding how much treatment information should be provided and understood, simple statements of whether an outcome or side-effect is likely to occur may be all that is required (Brazier, 1991).

BRAZIER, M. (1991) Competence, consent and proxy consents. In: Protecting the Vulnerable, Autonomy and Consent in Healthcare (eds M. Brazier \& M. Lobjoit) London \& New York: Routledge.

Grisso, T. \& Applebaum, P. S. (1995) A comparison of standards for assessing patients' capacities to make treatment decisions. American Journal of Psychiatry, 152, 1033-1038.

JONES, G. H. (1995) Informed consent in chronic schizophrenia. British Journal of Psychiatry, 167, 565-568.

RE C (1994) Adult: Refusal of Treatment; I WLR 290.

\section{PRiSM, Institute of Psychiatry}

K. SUTHERBY

London SE5 $8 A F$

Maudsley Hospital

G. SZMUKLER

London SE5 $8 A Z$

Trinity Hall

A. HALPERN

Cambridge CB2 1TJ

\section{Lithium revisited}

SIR: Scepticism about the evidence base for the value of lithium is overdue and well reviewed in the editorial by Moncrieff (1995). My doubts are increased by the methodological problems of removing bias from randomised controlled trials of lithium.

Although patients and healthy volunteers do not seem to be very good at identifying whether they are taking lithium or placebo in a clinical trial (Calil et al, 1990), it is the unblinding of raters which produces bias in clinical trials. In a study of lithium prophylaxis, patients' relatives' guesses far exceeded 
chance expectancy (Stallone et al, 1975). Contact with trial lithium patients, therefore, can lead to unblinding.

As the Cochrane Collaboration proceeds in its systematic review of clinical trials it has sought to determine whether controlled trials are properly randomised. In the Cochrane Pregnancy and Childbirth Database evidence of complete randomisation is associated with less treatment effect (Schulz et al, 1995). However, it may be necessary to conclude that a truly double-blind trial of lithium cannot be performed (Double, 1995).

Cal.ll, H. M., Zwicker, A. P. \& Klepacz, S. (1990) The effects of lithium carbonate on healthy volunteers: Mood stabilization? Biological Psychiatry, 27, 711-722.

DOuBLE, D. B. (1995) Unblinding in trials of the withdrawal of anticholinergic agents in patients maintained on neuroleptics. Journal of Nervous and Mental Disease, 183, 599-602.

MONCRIEFF, J. (1995) Lithium revisited. A re-examination of the placebo-controlled trials of lithium prophylaxis in manicdepressive disorder. British Journal of Psychiatry. 167, 569-573.

Schulz, K. F., Chalmers, I., Hayes, R. J., et al (1995) Dimensions of methodological quality associated with estimates of treatment effects in controlled trials. Journal of the American Medical Association, 273, 408-412.

Stallone, F., Mendlewicz, J. \& Fieve, R. R. (1975) Doubleblind procedure: an assessment in a study of lithium prophylaxis. Psychological Medicine. 5, 78-82.

D. B. DOUBLE

Community Mental Health Care Directorate

East Glade Centre

Sheffield S12 4QN

SIR: The editorial by Moncrieff (1995) contained a number of errors in reference to our paper (Coppen et al, 1971) on a prospective trial of lithium in the prophylaxis of unipolar and bipolar patients.

The report was concerned with 68 patients who completed the trial. The patients' plasma lithium was regularly monitored and it was found that six patients were poor compliers with inadequate or absent lithium levels. The results were still highly significant after adding these poor compliers. Thirteen patients dropped out of the trial during the initial 16 weeks of the trial, two were on lithium and 11 on placebo. A global rating of response was made independently by a social worker and the psychiatrist in charge of the patients. The two ratings were highly concordant. Eighty-six per cent of lithium patients were rated as showing little or no morbidity compared to only $8 \%$ of the placebo group. Similar results were found for unipolar and bipolar patients analysed separately. Other indices of response included time spent in hospital or with an out-patient episode and other treatment required. They all indicated a highly significant difference between the lithium and placebo patients. A particularly striking difference was found in the use of electroconvulsive therapy; no patient on lithium required this therapy as compared to $43 \%$ of the placebo group.

Following our trial we set up a mood disorder clinic in our unit and follow-up studies after many years have shown a very low morbidity in these patients. (Coppen \& Abou-Saleh, 1988) and as Professor Goodwin pointed out a very low suicide rate.

The most comprehensive meta-analysis of lithium treatment is by Davis et al (1993) using only double blind, random assignment, placebo controlled studies. In eight studies of maintenance treatment by lithium in unipolar depression they found an improvement in response rate (compared to placebo) of $34 \%\left(P<3 \times 10^{-9}\right)$; in bipolar illness (10 studies) they found a difference of $55 \%$ in response rate $\left(P<10^{-29}\right)$. They comment that this is roughly the order of magnitude of improvement shown with streptomycin treatment in comparison to bed rest alone for patients with tuberculosis.

The poor results of management of mood disorder may be attributed to the medical profession who, by and large, have failed to adequately treat the common, serious and potentially lethal conditions of depressive and mood disorders.

Coppen, A., Noguera, R., Balley J., et al (1971) Prophylactic lithium in affective disorders. Lancet, ii, 275-279.

\& ABOU-SALEH, M.T. (1988) Lithium therapy: from clinical trials to practical management. Acta Psychiatrica Scandinavica, 78, 756-762.

Davis, J. M., Wong, Z., \& Janicak, P.G. (1993) A quantitative analysis of clinical drug trials for the treatment of affective disorders. Psychopharmacology Bulletin, 29, 175-181.

MONCRIEFF, J. (1995) Lithium revisited. British Journal of Psychiatry, 167, 569-573.

\section{Walnut Close \\ Epsom, Surrey KT18 5JL}

SIR: It seems possible to me that the results of the early trials of lithium were influenced by the highly emotional climate in which they took place. In the 1960s and '70s, the so-called Cinderella of psychopharmacology was a pioneering drug, a cause célèbre. Handicapped by its toxicity problems and lack of interest from drug companies, it took on something of the mantle of the depressives it treated, and champions emerged to rescue its reputation and fight for its recognition.

In the Baastrup et al study of 1970, for example, patients who sensed from the side-effects that they 